University of Nebraska - Lincoln

DigitalCommons@University of Nebraska - Lincoln

Publications from USDA-ARS / UNL Faculty

U.S. Department of Agriculture: Agricultural

Research Service, Lincoln, Nebraska

2017

\title{
Sublethal exposure, insecticide resistance, and community stress
}

\author{
Raul Narciso C. Guedes \\ Universidade Federal de Vicosa, guedes@ufv.br \\ Spencer S. Walse \\ USDA-ARS, spencer.walse@ars.usda.gov \\ James E. Throne \\ USDA-ARS, Manhattan, KS, james.throne@ars.usda.gov
}

Follow this and additional works at: https://digitalcommons.unl.edu/usdaarsfacpub

Guedes, Raul Narciso C.; Walse, Spencer S.; and Throne, James E., "Sublethal exposure, insecticide resistance, and community stress" (2017). Publications from USDA-ARS / UNL Faculty. 1983.

https://digitalcommons.unl.edu/usdaarsfacpub/1983

This Article is brought to you for free and open access by the U.S. Department of Agriculture: Agricultural Research Service, Lincoln, Nebraska at DigitalCommons@University of Nebraska - Lincoln. It has been accepted for inclusion in Publications from USDA-ARS / UNL Faculty by an authorized administrator of DigitalCommons@University of Nebraska - Lincoln. 


\section{Sublethal exposure, insecticide resistance, and community stress Raul Narciso C Guedes ${ }^{1,2}$, Spencer S Walse ${ }^{2}$ and James $\mathrm{E}$ Throne ${ }^{2}$}

Insecticides are an invaluable pest management tool and anthropogenic stressors of widespread environmental occurrence that are subject to biased perceptions based on the targeted application, market value of use, and regulatory requirements. As a result, short-term and simplistic efforts focusing on lethal effects toward individual species and populations prevail. Holistic and comprehensive studies exploring rather common sublethal insecticide exposures are rare, particularly considering their potential role in structuring populations and communities in diverse environmental settings and potentially interfering in a range of ecological interactions. Studies on insecticide resistance, for example, do not go beyond population-based studies, disregarding temporal and spatial effects in the associated community, and rarely considering the whole of sublethal exposure. Some of these knowledge gaps are here recognized and explored.

\begin{abstract}
Addresses
${ }^{1}$ Departamento de Entomologia, Universidade Federal de Viçosa, Viçosa, MG 36570-900, Brazil

${ }^{2}$ USDA, Agricultural Research Service, San Joaquin Valley Agricultural Sciences Center, 9611 South Riverbend Avenue, Parlier, CA 936489757, United States
\end{abstract}

Corresponding author: Guedes, Raul Narciso C (guedes@ufv.br,rncguedes@gmail.com)

Current Opinion in Insect Science 2017, 21:47-53

This review comes from a themed issue on Pests and resistance

Edited by Thomas W Sappington and Nicholas John Miller

For a complete overview see the Issue and the Editorial

Available online 22nd May 2017

http://dx.doi.org/10.1016/j.cois.2017.04.010

2214-5745/๑ 2017 Elsevier Inc. All rights reserved.

This document is a U.S. government work and is not subject to copyright in the United States.

\section{Insecticides, sublethal exposure, and stress response}

Popular concepts and their perception have far-reaching consequences. Such seems to be the case with insecticides, which are popularly defined as a substance or chemical that kills insects. Curiously, this prevailing notion is at odds with the technical definition of an insecticide used by regulatory agencies as "any substance or mixture of substances intended for preventing, destroying, repelling, or mitigating any insect pest" (e.g., US Federal Insecticide, Fungicide, and Rodenticide Act). The latter tends to be overshadowed by the former even within professional circles [1,2]. The subliminal message and appeal of the popular notion of insecticides is an overemphasis on the killing of insects leading to a relative neglect in recognizing the importance of sublethal effects of these compounds [3-5, $\left.6^{\bullet \bullet}\right]$. This shortcoming exists not only for conventional (synthetic) insecticides, but also for bioinsecticides, reduced-risk insecticides, and insecticidal proteins.

Although frequently intended to cause the quick mortality of a targeted pest species, insecticide residue degrades over time reducing the initial (lethal) deposit to a (sublethal) residue, and/or may generate new structurally-derived residues exhibiting biological activity. Furthermore, the initial application is aimed at a particular target or limited number of target species, but non-target species will be subjected to sublethal doses and/or exposure at the onset of the application (Figure 1). This (sublethal) insecticide exposure can lead to adverse consequences to the exposed organisms, but not necessarily so. Responses to such a stress are bound to vary in a dose/concentration-dependent manner between lower and upper thresholds (i.e., the basic dose/concentration-response relationship of toxicology), outside of which the organism is unaffected by the exposure, or too much affected reaching around $100 \%$ response. However, within the said thresholds and apart from the expected detrimental effects, an inverted response trend may occur, potentially benefiting either the exposed organism or its progeny, depending on the physiological trade-off involved [8,9].

A hierarchical view of insecticide stress response is helpful in recognizing the potential consequences of insecticide exposure, and particularly of sublethal exposure $\left[6^{\circ \bullet}\right]$. Upon reaching and penetrating an organism, the insecticide will likely affect its physiology or that of associated symbiont(s) $\left[6^{\bullet \bullet}, 9\right]$. Interacting conspecifics are also likely to be affected, eliciting a population-level response (e.g., insecticide resistance and control failure), that can eventually be translated into a community-level consequence via direct or indirect effects of insecticide exposure $\left[6^{\circ \bullet}\right]$ (Figure 2). The recently conceived conceptual construct of the adverse outcome pathway reflects the concern of linking a direct molecular initiating event 
Figure 1

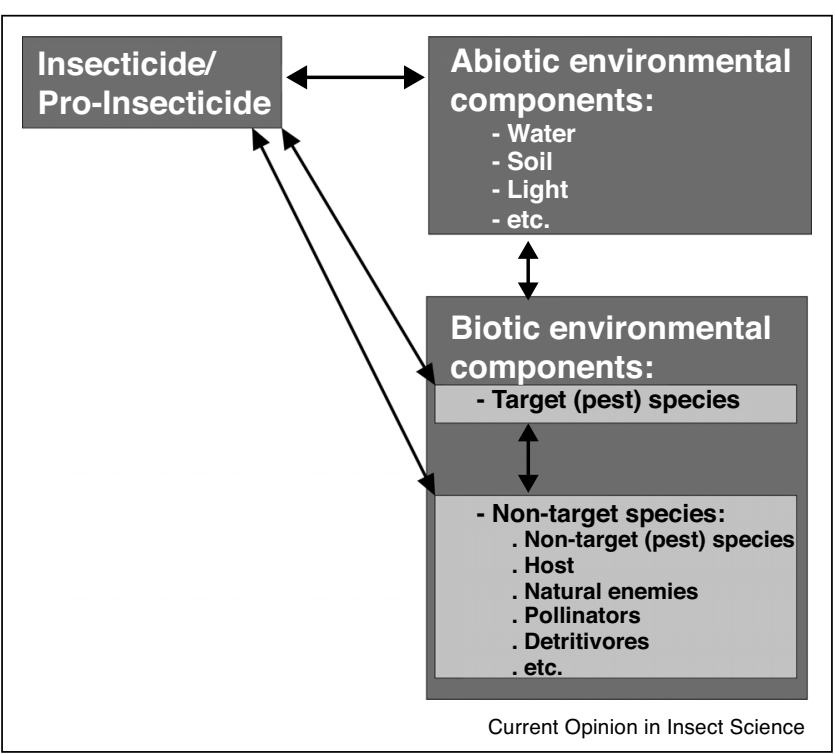

The nature of insecticide stress arising from the potential interactions between an insecticide and environmental components, as well as the potential interactions among environmental components under the direct influence of the insecticide.

to an adverse outcome at a higher biological level of organization relevant to risk assessment [10,11]. This promising construct, which recognizes the progress of toxicity events across hierarchical scales of biological organization, does have its limitations including its overly (unrealistic) simplicity and reductionism (e.g., ignoring parallel cascades and intercrossing pathways) [10,11]. An additional shortcoming of this conceptual construct is that it neglects to recognize that a stress response does not necessarily lead to an adverse outcome, but may also hierarchically elicit non-toxic (and non-adverse) responses [7,8,10-12]. The stress response will vary with the individual and its susceptibility, the insecticide and its dose/concentration, and the environmental context in which exposure takes place. Insecticide resistance provides an illustrative context worthy of exploring.

\section{Insecticide resistance under sublethal exposure}

Insecticide resistance is essentially a genetic change in response to selection by a toxicant, the insecticide, among individuals of a given species, the potential consequence of which is impaired chemical control in the field [13]. Although selection for insecticide resistance is frequently associated with differential mortality among individuals, the phenomenon refers to differential survival and reproduction. Therefore, insecticide resistance can be achieved not only by the use of lethal insecticide concentrations eliminating susceptible individuals, but also by sublethal exposure favoring survival and reproduction of the resistant individuals.

The role and potential consequences of sublethal insecticide exposure for insecticide resistance are frequently neglected, but their relevance may be recognized on three fronts. First, sublethal exposure may delay selection for major single gene resistance while favoring multifactorial or polygenic resistance [14]. This is the likely consequence of the accumulation of low-level resistance genes and mechanisms (e.g., reduced penetration, behavioral avoidance, etc.) allowing small increases in the magnitude of insecticide resistance distinct from the selection of a major mutation (e.g., altered target site sensitivity) leading to a high resistance $[14,15]$. Furthermore, sublethal stress may also contribute to resistance by promoting increased mutation rates of genes involved in DNA repair, as observed in bacteria and weeds $\left[14,16^{\bullet}, 17\right]$. Insecticides involved in oxidative stress, such as the fumigant phosphine, seem like good candidates for investigation as they may directly or indirectly compete for energy from NAD $(\mathrm{P}) \mathrm{H}$ and nucleotide triphosphates necessary for performance of DNA repair enzymes [14,18,19].

Sublethal insecticide exposure may influence insecticide resistance beyond selection of resistant individuals via two additional phenomena: insecticide-induced hormesis, and induction/cross-induction of detoxification enzymes. Neither is usually considered in studies of

Figure 2

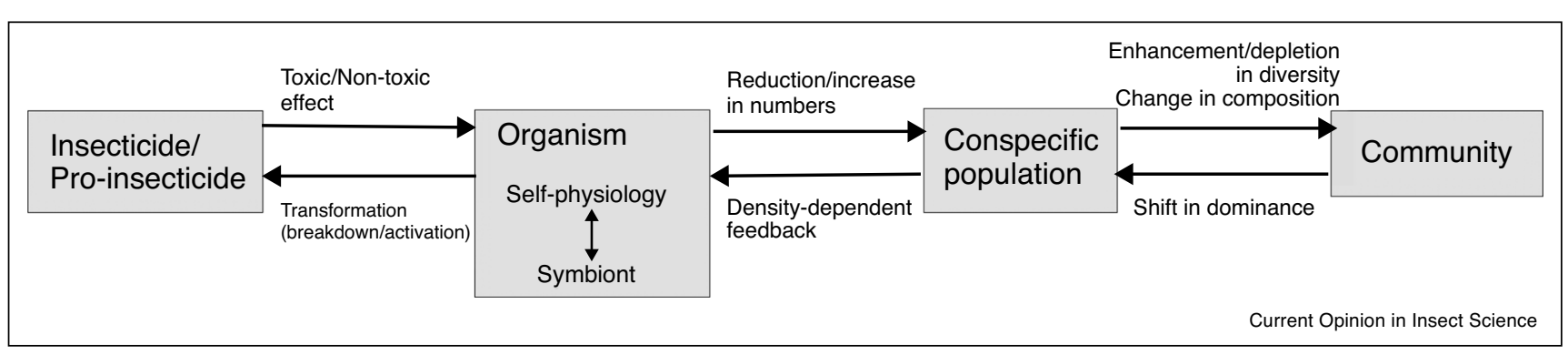

The chain of potential hierarchical interactions and responses sparked by an insecticide. 
insecticide resistance, but both have management and environmental implications. Insecticide-induced hormesis is a biphasic dose-response relationship characterized by a reversal in response between low and high doses of a stressor, such as an insecticide $\left[6^{\bullet \bullet}, 8,9\right]$. The direct relevance of hormesis to insecticide resistance is its occurrence in insecticide-resistant populations, as demonstrated by pyrethroid-resistant weevils [20]. This may take place upon failure of the insecticide to suppress the insecticide-resistant population, with the sublethal exposure falling in the range of hormesis for that population. The end result is the field application rate not only leading to control failure, but actually boosting the growth of the resistant population.

The possibility of induction and cross-induction of detoxification enzymes is also of interest. These are broadly recognized as important insecticide resistance mechanisms upregulated (and overexpressed) in several resistant populations and prevailing against certain insecticides like neonicotinoids [21]. However, these detoxification enzymes are inducible, and the induction may still take place in insecticide-resistant populations sublethally exposed to insecticide, priming the insects against further exposure to the same or even other compounds, a phenomenon also referred to as hormetic priming or conditioning $\left[22,23^{\circ}, 24\right]$. Imidacloprid priming was recently recognized in the green peach aphid with the involvement of esterases (E4) and cytochrome P450 (CYP6CY3) [23 $3^{\circ}$. The priming may take place between distinct stressors following a cross-induction pattern and may occur in non-resistant populations as well, allowing enhanced insecticide tolerance $\left[23^{\circ}, 24,25\right]$. This risk is already an expressed concern for mosquito control where prior exposure to urban pollutants and agriculture pesticides can shape the response to insecticide exposure and eventual selection for resistance [26-28]. As in hormetic priming, forewarned is forearmed. The implications of the phenomenon deserve attention as it may contribute to and even shape inadvertent selection for insecticide resistance in non-targeted pest species, as observed in indoxacarb-resistant maize weevils and Bt-resistant fall armyworm [29,30], apart from potentially leading to crosstolerance in insecticide-resistant populations.

\section{Dual species interactions}

Insecticide resistance is a broadly recognized ecological backlash resulting from intensive insecticide use and overuse/misuse. Therefore its study is a priority, where the proactive role of the Insecticide Resistance Action Committee is but an industry response to the challenge [31]. Curiously though, the investigative effort on insecticide resistance focuses solely on the target species neglecting its interactive context and the chemical landscape in which it takes place. This reductionist approach is understandable from an experimental perspective, since it is simpler and cheaper. However, it is wholly unrealistic, because single isolated species and/or chemicals do not exist alone in nature, and sublethal exposure to chemicals prevails.

Among co-occurring species, heterospecific interactions may be affected by insecticides. Host-parasite interactions allow for good examples, as does interspecific competition between arthropod pest species. Although examples of insecticides affecting arthropod-natural enemy interactions are frequent, the potential insecticide effects on host plant-arthropod pest interactions and plant-pestnatural enemy tri-trophic interactions are also potentially important $\left[6^{\circ}\right]$. For example, there is only preliminary evidence that insecticides may interfere with volatile emission by host plants either enhancing or compromising arthropod pest foraging [32-34], a growing concern with anthropogenic compounds in general $\left[35,36^{\circ}\right]$. The potential pesticide induction of (and de novo) extrusion of linear furanocoumarins to the leaf surface of host plants is but an example deserving of attention [37]. Furthermore, insecticides can of course impair stimuli reception and/or processing by insects, compromising such interactions $\left[6^{\bullet \bullet}, 38\right]$, the specifics of which will vary with the level of insecticide resistance and underlying mechanism involved.

Shifts in species dominance may also be mediated by sublethal insecticide exposure due to differences in tolerance, and resistance, between insect species and populations. Insecticides, as agents of disturbance or stress, may alter ecological relationships leading to shifts in dominance of competing species, as reported among mosquitoes and grain beetles $\left[39,40^{\circ}\right]$. Such direct evidence is rare, but gives credence to the intermediate disturbance hypothesis: intermediate levels of environmental disturbance are predicted to result in increased species diversity while compromising the previously dominant species $\left[6^{\bullet \bullet}, 40^{\bullet}\right]$. The rationale is the same if insecticide-resistant populations of different species are involved.

Insecticide resistance and sublethal exposure may also contribute to secondary pest outbreaks, which is the increase in abundance of a non-targeted pest species after insecticide application against the targeted species. Pyrethroid-induced hormesis for instance seems to favor outbreaks of the southern red mite in coffee plantations upon pyrethroid use against the coffee leafminer [41]. In addition, insecticide application against a targeted species will also likely lead to sublethal insecticide exposure of an already resistant population of another co-existing pest species, promoting its outbreak. Current use of Bacillus thuringiensis toxins (Bt toxins; or $\mathrm{Bt}$ for short) in transgenic soybean in Brazil, for instance, might be favoring further increase in stink bug outbreaks in the country, a nontargeted group of pest species. Past use of Bt maize expressing Cry1A toxins against budworms likely allowed 
inadvertent cross-selection to Cry1F in the fall armyworm. Both circunstances likely aggravated recent outbreaks of stink bugs and armyworm in the country since the introduction of this technology justifying the stated concern.

\section{Community stress}

Anthropogenic stress agents, particularly insecticides, are rather frequent components of urban and agricultural ecosystems, combining to form a complex chemical landscape where an assemblage of species populations coexist. If these populations do interact with one another, they integrate as a community that is subject to the landscape and its (biologically-active) chemical components. Thus, these biologically-active chemicals are potential contributors to shaping community structure. The underlying mechanisms involved in this process are a focus of debate in ecotoxicology, besides constituting an unplanned evolutionary experiment based on the adaptive mismatch between undisturbed and anthropogenically disturbed environments [42]. Research with bacterial communities and aquatic ecosystems has been intensive, giving credence to this notion [42-46], in sharp contrast with the attention paid to pesticides and arthropods in urban and agricultural ecosystems $\left[6^{\bullet \bullet}\right]$.

Sublethal (insecticide) exposure and insecticide resistance are important components in shaping community stress through inadvertent selection, hormesis, hormetic priming, induced shift in dominance, impairment of species interactions, and eventual pest outbreaks, as already discussed. Most research on insecticide-induced community stress carried out with terrestrial arthropods has focused on natural enemies of arthropod pest species, frequently even neglecting their associated host complex $\left[6^{\bullet \bullet}, 47,48\right]$. Besides non-targeted pest species, insecticides are also likely to affect direct and indirect competitors, their host organisms, detritivorous species, and pollinators, organisms potentially important to agricultural yield and disease transmission. The few available studies on terrestrial arthropod communities are relatively short-term, encompassing no more than two or three seasons, and thus less likely to detect community-wide effects since such effects usually take longer to express. Among these studies, the impact of Bt toxins in transgenic crops have received the bulk of recent attention.

Pre-market assessments of the risk associated with Bt crops are a current regulatory requirement in several countries, which encourages assessment of community stress. However, their community effects tend to be negligible, and the short-term assessment is a likely reason for that $[45,49-52]$. Nonetheless, post-marketing 5-10 year assessments of community effects are also required in some countries, and such data sets still must be duly explored. As with any modification in cultivation system, community changes are expected, but they may be negligible. Nonetheless, considering the intended negative impact on at least one key arthropod pest species targeted by the transgenic Bt plants, changes in this targeted species and associated food-web are expected and should be evident, particularly in long-term assessments. Curiously, we are aware of only a single study exploring food web analysis in community stress by $\mathrm{Bt}$

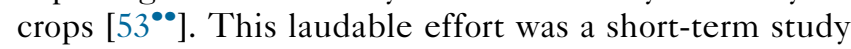
focusing on broad trophic groups and taxa, compromising the potential resolution of the analyses for detecting species-associated food-web effects, while understandably favoring the search for broader patterns across Central Europe. Nevertheless, the approach is most welcome and merits further use.

\section{Knowledge gaps \& future perspectives}

The prevailing negative perception of insects in human society [54,55] and use of insecticides as killing agents arguably contribute to the insecticide debate, as well as research biased towards oversimplified lethal assessments and short-term studies focusing on individual organisms and populations of arthropod pests, some of their natural enemies, and pollinators. The market value of insecticides as the dominant pest management tool in use for the last 70+ years, the associated agrochemical industry and user interests, together with regulatory demands, have largely reinforced and shaped insecticide research along the current lines.

The inherent conflict of interest existing in insecticide research, where the agrochemical companies are the main research sponsors, and a user-oriented focus favor short-term studies on efficacy and on immediate localized (and suspected) impacts directly influencing pest control or yield production. This scenario neglects the prevalence of sublethal exposure in nature, and the complex environmental context in which this exposure takes place among a myriad of co-occurring species and biologically active chemicals. Thus, the role of sublethal exposure in insecticide resistance remains largely unexplored. Furthermore, sublethal insecticide stress is bound to interfere with environmental context and ecological interactions, particularly when long-term exposure, or more precisely persistent short-term exposure, is considered.

An overhaul of the current methods and approaches used in insecticide research should be considered exploring a more holistic and comprehensive theoretical framework. The experimental methods necessary for this approach necessarily require expertise that goes beyond the current focus on proximate mechanisms at the biochemical and physiological levels, which are a common emphasis in current Insecticide Toxicology courses within Entomology (Post-)Graduate Programs. The ultimate consequences of pesticide exposure, particularly sublethal exposure, are paramount but require knowledge of 
life-history trade-offs, behavioral ecology, and population and community ecology; the mediating role of natural and engineered environmental chemistries also should not be neglected, as they are critical to arthropod-arthropod and arthropod-host interactions.

The simultaneous assessment of sublethal toxicological endpoints, such as effective median concentrations for population growth rate and the balance among the lifehistory traits involved, is labor intensive. They usually require the use of life tables, but are pivotal for studies on insecticide-induced hormesis, among others. However, these methods have been greatly simplified and surrogates exist making then more cost-effective $\left[6^{\bullet \bullet}, 7\right]$. Studies on insect assemblages and communities are also labor intensive and require high-level taxonomic expertise because identification at genus and species level is important for high resolution detection of responses. Multivariate statistical methods are required for such studies with multiple species, multiple chemical compounds, and their interactions. Furthermore, more recent approaches such as food-web and social network analyses are under current development exhibiting unrealized potential for future endeavors in understanding pesticide-arthropod interactions.

The proposed theoretical framework should expand the notion of adverse outcome pathways to explore stress response pathways linking molecular (primary and secondary) events taking place within co-occurring species, their potentially intercrossing and parallel pathways, and their intertwined hierarchical consequences beyond the population level. The notion is bold, the challenges and expertise required may be daunting at first, but rewards greatly surpass the challenges. The relevance of the subject goes well beyond pest management. Anthropogenic compounds, particularly pesticides, are a prevalent landscape feature, whose potential eco-evolutionary consequences have yet to be comprehended. Thus, let there be light!

\section{Acknowledgements}

The authors would like to thank Drs. Tom Sappington and Nick Miller for the invitation to prepare this contribution; the comments and suggestions provided by Dr. T. Sappington and an anonymous reviewer were also greatly appreciated. Financial support was provided by the $\mathrm{CNPq}$ (Brazilian Ministry of Science and Technology), CAPES (Brazilian Ministry of Education), and USDA-ARS. The research was supported in part by an appointment to the Agricultural Research Service (ARS) Research Participation Program administered by the Oak Ridge Institute for Science and Education (ORISE) through an interagency agreement between the U. S. Department of Energy (DOE) and the U.S. Department of Agriculture (USDA). ORISE is managed by ORAU under DOE contract number DESC0014664. All opinions expressed in this paper are the author's and do not necessarily reflect the policies and views of USDA, ARS, DOE, or ORAU/ ORISE. Mention of trade names or commercial products in this publication is solely for the purpose of providing specific information and does not imply recommendation or endorsement by the U.S. Department of Agriculture. USDA is an equal opportunity provider and employer.

\section{References and recommended reading}

Papers of particular interest, published within the period of review, have been highlighted as:

- of special interest

-. of outstanding interest

1. Enserink M, Hines PJ, Vignieri SN, Wigginton NS, Yeston JS: The pesticide paradox. Science 2013, 341:728-729.

2. Devine GJ, Furlong MJ: Insecticide use: contexts and ecological consequences. Agric. Hum. Values 2007, 24:281-306.

3. Amarasekare KG, Shearer PW, Mills NJ: Testing the selectivity of pesticide effects on natural enemies in laboratory bioassays. Biol. Control 2016, 102:7-16.

4. Macfadyen S, Banks JE, Stark JD, Davies AP: Using semifield studies to examine the effects of pesticides on mobile terrestrial invertebrates. Annu. Rev. Entomol. 2014, 59:383-404

5. Hardin MR, Benrey B, Coll M, Lamp WO, Roderick GK, Barbosa P: Arthropod pest resurgence: an overview of potential mechanisms. Crop Prot. 1995, 14:3-18.

6. Guedes RNC, Smagghe G, Stark JD, Desneux N: Pesticide-. induced stress in arthropod pests for optimized integrated pest management programs. Annu. Rev. Entomol. 2016, 61:120.

Comprehensive review that explores pesticide stress in arthropods, particularly pest species. It draws attention to the importance and current research shortcomings of the subject, hierarchically exploring the cascade of potential direct and indirect effects involved.

7. Guedes RNC, Cutler GC: Insecticide-induced hormesis and arthropod pest management. Pest Manage. Sci. 2014, 70:690697.

8. Cutler GC, Rix RR: Can poisons stimulate bees? Appreciating the potential of hormesis in bee-pesticide research. Pest Manage. Sci. 2015, 71:1368-1370.

9. Douglas AE: Multiorganismal insects: diversity and function of resident microorganisms. Annu. Rev. Entomol. 2015, 60:17-34.

10. Vinken $\mathrm{M}$ : The adverse outcome pathway concept: a pragmatic tool in toxicology. Toxicology 2013, 312:158-165.

11. Groh KJ, Carvalho RN, Chipman JK, Denslow ND, Halder M, Murphy CA, Roelofs D, Rolaki A, Schirmer K, Watanabe KH: Development and application of the adverse outcome pathway framework for understanding and predicting chronic toxicity: I. Challenges and research needs in ecotoxicology. Chemosphere 2015, 120:764-777.

12. Jennings $P$ : Stress response pathways, toxicity pathways and adverse outcome pathways. Arch. Toxicol. 2013, 87:13-14.

13. Guedes RNC: Insecticide resistance, control failure likelihood, \& the First Law of Geography. Pest Manage. Sci. 2017, 73:479484 http://dx.doi.org/10.1002/ps.4452.

14. Gressel J: Low pesticide rates may hasten the evolution of resistance by increasing mutation frequencies. Pest Manage. Sci. 2011, 67:253-257.

15. Nansen C, Baissac O, Nansen M, Powis K, Baker G: Behavioral avoidance-will physiological insecticide resistance level of insect strains affect their oviposition and movement responses? PLoS One 2016, 11:e0149994.

16. Ram $Y$, Hadany L: Stress-induced mutagenesis and complex adaptation. Proc. R. Soc. B 2014, 281:20141025.

Modelling study exploring the theoretical balance between adaptability and adaptedness using an asexual population crossing a fitness landscape. The findings support the hypothesis that stress-induced mutagenesis promotes adaptation, and the model allows quantitative predictions of the rate of adaptation under different mutational strategies.

17. Torres-Barceló C, Cabot G, Oliver A, Buckling A, Maclean RC: A trade-off between oxidative stress resistance and DNA repair plays a role in the evolution of elevated mutation rates in bacteria. Proc. R. Soc. B 2013, 280:20130007. 
18. Liu T, Li L, Zhang F, Wang Y: Transcriptional inhibition of the catalase gene in phosphine-induced oxidative stress in Drosophila melanogaster. Pestic. Biochem. Physiol. 2015, 124:1-7.

19. Sciuto AM, Wong BJ, Martens ME, Hoard-Fruchey H, Perkins MW: Phosphine toxicity: a story of disrupted mitochondrial metabolism. Ann. N. Y. Acad. Sci. 2016, 1374:41-51.

20. Guedes NMP, Tolledo J, Corrêa AS, Guedes RNC: Insecticideinduced hormesis in an insecticide-resistant strain of the maize weevil, Sitophilus zeamais. J. Appl. Entomol. 2010, 134:142-148.

21. Bass C, Denholm I, Williamson MS, Nauen R: The global status of insect resistance to neonicotinoid insecticides. Pestic. Biochem. Physiol. 2015, 121:78-87.

22. Costantini D, Monaghan P, Metcalfe NB: Prior hormetic priming is costly under environmental mismatch. Biol. Lett. 2014, 10:20131010.

23. Rix RR, Ayyanath MM, Cutler GC: Sublethal concentrations of - imidacloprid increase reproduction, alter expression of detoxification genes, and prime Myzus persicae for subsequent stress. J. Pest Sci. 2016, 89:581-589.

This study tested whether changes in gene expression of insecticide detoxification and general stress response occur across generations of green peach aphid exposed to imidacloprid concentrations at the hormetic range. Intermittent changes in expression of detoxification and stress response genes were observed, potentially priming the insects to withstand subsequent stress.

24. Costantini D: Does hormesis foster organism resistance to extreme events? Front. Ecol. Environ. 2014, 12:209-210.

25. Hua J, Jones DK, Relyea RA: Induced tolerance from a sublethal insecticide leads to cross-tolerance to other insecticides. Environ. Sci. Technol. 2014, 48:4078-4085.

26. Poupardin R, Reynaud S, Strode C, Ranson H, Vontas J, David J: Cross-induction of detoxification genes by environmental xenobiotics and insecticides in the mosquito Aedes aegypti: impact on larval tolerance to chemical insecticides. Insect Biochem. Mol. Biol. 2008, 38:540-551.

27. Poupardin R, Riaz MA, Jones CM, Chandor-proust A, Reynaud S, David J: Do pollutants affect insecticide-driven gene selection in mosquitoes? Experimental evidence from transcriptomics. Aquat. Toxicol. 2012, 114-115:49-57.

28. Nkya TE, Akhouayri I, Kisinza W, David J: Impact of environment on mosquito response to pyrethroid insecticides: facts, evidences and prospects. Insect Biochem. Mol. Biol. 2013, 43:407-416.

29. Haddi K, Mendonca LP, Dos Santos MF, Guedes RNC, Oliveira EE Metabolic and behavioral mechanisms of indoxacarb resistance in Sitophilus zeamais (Coleoptera: Curculionidae). J. Econ. Entomol. 2015, 108:362-369.

30. Santos-amaya OF, Rodrigues JVC, Souza TC, Tavares CS: Resistance to dual-gene Bt maize in Spodoptera frugiperda: selection, inheritance, and cross-resistance to other transgenic events. Sci. Rep. 2015, 5:18243.

31. Sparks TC, Nauen R: IRAC: mode of action classification and insecticide resistance management. Pestic. Biochem. Physiol. 2015, 121:122-128.

32. Facknath S, Stewart-Jones A, Wright DJ: Neem chemicals disturb the behavioral response of Liriomyza huidobrensis to conspecific-induced potato volatiles. Pure Appl. Chem. 2009, 81:85-95.

33. Degenhardt DC, Greene JK: Influence of pyrethroid pesticide formulation on volatile emissions from cotton, Gossypium hirsutum L., leaves. J. Agric. Urban Entomol. 2012, 28:8-15.

34. Charleston DS, Gols R, Hordijk KA, Kfir R, Vet LEM, Dicke M: Impact of botanical pesticides derived from Melia azedarach and Azadirachta indica plants on the emission of volatiles that attract parasitoids of the diamondback moth to cabbage plants. J. Chem. Ecol. 2006, 32:325-349.
35. Loreto F, Dicke M, Schnitzler J, Turlings TCJ: Plant volatiles and the environment. Plant Cell Environ. 2014, 37:1905-1908.

36. Jürgens $A$, Bischoff $M$ : Changing odour landscapes: the effect - of anthropogenic volatile pollutants on plant-pollinator olfactory communication. Funct. Ecol. 2016, 31:56-64 http://dx doi.org/10.1111/1365-2435.12774.

Review that explores the potential interference of anthropogenic pollutants in chemical communication between flowering plants and flower visitors. Such compounds may affect the chemical communication by interfering with plant signalling, directly interfering with the chemical signal, enhancing the background noise, and/or compromising signal perception and response. Current knowledge gaps and likely consequences are addressed.

37. Trumble JT, Millar JG, Ott DE, Carson WC: Seasonal patterns and pesticidal effects on the phototoxic linear furanocoumarins in celery, Apium graveolens L. J. Agric. Food Chem. 1992, 40:1501-1506.

38. Casida JE, Durkin KA: Neuroactive insecticides: targets, selectivity, resistance, and secondary effects. Annu. Rev. Entomol. 2013, 58:99-117.

39. Alto BW, Lampman RL, Kesavaraju B, Muturi EJ: Pesticideinduced release from competition among competing Aedes aegypti and Aedes albopictus (Diptera: Culicidae). J. Med. Entomol. 2013, 50:1240-1249.

40. Cordeiro EMG, Corrêa AS, Guedes RNC: Insecticide-mediated - $\quad$ shift in ecological dominance between two competing species of grain beetles. PLoS One 2014, 9:e100990.

Study exploring the effect of competition and insecticide stress in two species of grain beetles using intra and interspecific curves in additive and replacement series of insect density combinations. Overall, high conspecific densities favored insecticide activity, but the strength of the relationship differed with the species, and mediated a shift in dominance and competition outcome under intermediate (sublethal) insecticide concentrations.

41. Cordeiro EMG, Moura de ILT, Fadini MAM, Guedes RNC: Beyond selectivity: are behavioral avoidance and hormesis likely causes of pyrethroid-induced outbreaks of the southern red mite Olygonichus ilicis? Chemosphere 2013, 93:1111-1116.

42. Smith TB, Kinnison MT, Strauss SY, Fuller TL, Carroll SP: Prescriptive evolution to conserve and manage biodiversity. Annu. Rev. Ecol. Evol. Syst. 2014, 45:1-22.

43. Cary TL, Chandler GT, Volz DC, Walse SS, Ferry JL: Fipronilinduced male infertility in the meiobenthic harpacticoid copepod Amphiascus tenuiremis. Environ. Sci. Technol. 2004, 38:522-528.

44. Bunzel K, Liess M, Kattwinkel M: Landscape parameters driving aquatic pesticide exposure and effects. Environ. Pollut. 2014 186:90-97.

45. Singh AK, Dubey SK: Current trends in Bt crops and their fate on associated microbial community dynamics: a review. Protoplasma 2016, 253:663-681.

46. De Castro-Català N, Kuzmanovic M, Roig N, Sierra J, Ginebreda A Barceló D, Pérez S, Petrovic M, Picó Y, Schuhmacher M et al.: Ecotoxicity of sediments in rivers: invertebrate community, toxicity bioassays and the toxic unit approach as complementary assessment tools. Sci. Total Environ. 2016, 540:297-306.

47. Martin EA, Reineking B, Seo B, Steffan-Dewenter I: Pest control of aphids depends on landscape complexity and natural enemy interactions. PeerJ 2015, 3:e1095.

48. Martin EA, Reineking B, Seo B, Steffan-Dewenter I: Natural enemy interactions constrain pest control in complex agricultural landscapes. Proc. Natl. Acad. Sci. U. S. A. 2013 110:5534-5539.

49. Arias-Martín M, García M, Luciáñez MJ, Ortego F, Castañera P, Farinós GP: Effects of three-year cultivation of Cry1Abexpressing Bt maize on soil microarthropod communities. Agric. Ecosyst. Environ. 2016, 220:125-134.

50. Guo $Y$, Feng $Y$, Ge $Y$, Tetreau G, Chen X, Dong X, Shi W: The cultivation of Bt corn producing Cry1Ac toxins does not 
adversely affect non-target arthropods. PLoS One 2014, 9: e114228.

51. Kolseth A, Hertefeldt TD, Emmerich M, Forabosco F, Marklund S, Cheeke TE, Hallin S, Weih M: Influence of genetically modified organisms on agro-ecosystem processes. Agric. Ecosyst. Environ. 2015, 214:96-106.

52. Yaqoob A, Shahid AA, Samiullah TR, Rao AQ, Khan MAU, Tahir S, Mirza SA, Husnain T: Risk assessment of Bt crops on the nontarget plant-associated insects and soil organisms. Pest Manage. Sci. 2016, 96:2613-2619.

53. Szénási A, Pálinkás Z, Zalai M, Schmitz OJ, Balog A: Short-term

-• effects of different genetically modified maize varieties on arthropod: an experimental field assessment. Sci. Rep. 2014, 4:5315
The article reports the results of a two-year field study assessing the foodweb impact of genetically-modified (GM) maize plants. The complex and stable food webs persisted in maize (GM and non-GM). The food web structure also did not change in GM maize, as compared with non-GM maize, indicating that no short-term adverse effect occurred in this agricultural landscape.

54. Barua M, Gurdak DJ, Ahmed RA, Tamuly J: Selecting flagships for invertebrate conservation. Biodivers. Conserv. 2012, 21:1457-1476.

55. Lemelin RH, Harper RW, Dampier J, Bowles R: Humans, insects and their interaction: a multi-faceted analysis. Anim. Stud. J. 2016, 5:65-79. 